\title{
Homebound status among middle-aged and older adults with disabilities in ADLs and its associations with clinical, functional, and environmental factors
}

\author{
Iván De-Rosende Celeiro, Ph.D. ${ }^{\mathrm{a}, \mathrm{b}}$ SergioSantos-del-Riego, Ph.D. ${ }^{\mathrm{c}}$ Javier Muñiz \\ García, Ph.D. ${ }^{\text {d,e }}$
}

${ }^{a}$ Department of Health Sciences, University of A Coruña, A Coruña, Spain

${ }^{b}$ Service of Dependence and Personal Autonomy, Xunta de Galicia, A Coruña, Spain

${ }^{c}$ Department of Medicine, University of A Coruña, A Coruña, Spain

${ }^{d}$ University Institute of Health Sciences, University of A Coruña, A Coruña, Spain

${ }^{e}$ Biomedical Research Institute of A Coruña, A Coruña, Spain

\begin{abstract}
Background. Homebound status is associated with poor health, comorbidity, and mortality and represents a major challenge for health systems. However, its prevalence among people with disabilities in the basic activities of daily living (ADLs) is unknown.

Objectives. The objectives were to: (1) examine the prevalence of the homebound status among middle-aged and older adults with disabilities in ADLs, and (2) identify its clinical, functional, and environmental determinants.

Methods. This study included 221 community-dwelling subjects, aged $\geq 50$ years, who applied for long-term care services at the Office for Legal Certification of Long-term Care Need of Coruna (Spain). Each subject had a disability in ADLs and was interviewed by a trained examiner in the subject's home. The participants were considered homebound if they remained inside their home during the previous week.

Measures. Demographic, clinical, functional, and environmental factors. Multiple logistic regression was used to determine the factors associated with homebound status.

Results. The prevalence of homebound status was 39.8\%. A multivariate analysis revealed that the presence of architectural barriers at the home entrance (stairs [OR: 6.67, $p<0.001$ ] or a heavy door [OR: 2.83, $p=0.023]$ ), walking ability limitations (OR: $3.26, p=0.006$ ), and higher age (OR: $1.05, p=0.04$ ) were associated with homebound status.

Conclusions. Homebound status is a highly prevalent problem among middle-aged and older adults with disabilities in ADLs. Architectural factors in the home and walking ability limitations seem to be important predictors, suggesting that health care interventions should target home adaptations and mobility skills as a means to preventing or decreasing homebound status.
\end{abstract}

\section{Keywords}

Accessibility; Functional disability; Homebound status; Mobility; Prevalence 
The aging of the population and the steady growth in the number of people with disabilities expected for the 21 st century pose major challenges for health policies. Clinical experience suggests that home confinement is a common problem in the everyday life of people with major disabilities, particularly in people with limited basic ADLs. Homebound status has been associated with loneliness, ${ }^{1}$ depression, ${ }^{1-5}$ comorbidity, ${ }^{1,6}$ hospitalization, ${ }^{4,7}$ and worse self-reported health status ${ }^{1,8}$; moreover, it is a risk factor for mortality. $3,7,8$

Previous research has estimated the prevalence of homebound status in the older population, ${ }^{1,4,8-11}$ using diverse definitions. ${ }^{6}$ Several studies have defined being homebound as going out of the house once a week or less, with a prevalence ranging between $7.5 \%$ and $19 \%^{1,4,9,11}$; the prevalence was below $5 \%$ when this frequency was less than once a week. ${ }^{8,12}$ In a community sample of older people, $3.5 \%$ of the participants remained inside the home in the last month. ${ }^{10}$ The rate of homebound people was higher in the frail older population $(23.2 \%) .{ }^{5}$ Regarding the factors associated with homebound status, most studies have focused on personal characteristics and clinical variables. Being homebound was associated with older age, ${ }^{1,4,9,13}$ female gender, ${ }^{1,3,8,9,13}$ and being widowed. ${ }^{4,8}$ Other studies have reported more chronic health conditions $^{4,6}$ and cognitive ${ }^{1,6}$ or sensory ${ }^{1}$ impairments in the homebound group. However, relatively little is known regarding the role of environmental factors. With respect to the architectural environment, the homebound participants were more likely to have stairs at the home entrance in a sample of people aged $\geq 75$ years ${ }^{1}$; another study in urban older people showed that being homebound was associated with living on a higher floor. ${ }^{10}$

Despite the large number of studies on the prevalence and determinants of the homebound status in older people, no data exist on this topic among middle-aged and older adults with disabilities that prevent them from performing ADLs. Providing epidemiological information on homebound people could guide prevention and management health strategies. Accordingly, this study aimed to examine the prevalence of the homebound status and to identify its clinical, functional, and environmental determinants among middle-aged and older adults with disabilities in ADLs.

\section{Methods}

\section{Setting}

The study was carried out by a trained examiner from the Office for Legal Certification of Long-term Care Need of Coruña (Spain) in the applicant's home. This certification is required for access to the services of the Spanish long-term care system and consists of a standardized evaluation, known as the assessment of the dependence status. The study area consisted of a city (Coruña) and six bordering suburban and rural municipalities in northwestern Spain, with a total population of 330,877 individuals in 2015 (40.8\%, aged $\geq 50$ years).

\section{Participants and data collection}

For the participants, the inclusion criteria were as follows: (i) application for a certification of long-term care need at the office described above, (ii) aged $\geq 50$ years, (iii) living in their homes, and (iv) a disability in ADLs, which is defined as the need for personal help to perform one or more of the following activities of the Katz Index: feeding, bathing, dressing, toileting, and transferring. ${ }^{14}$

The assessment of the dependence status is an official evaluation procedure composed of three steps: (i) a review of the participant's medical records, which were completed by a primary care physician and included diagnosed health conditions and impairments, (ii) a face-to-face interview with the applicants and their caregivers, and (iii) the use of a screening instrument. Uniform criteria are applied nationwide. The collected information was detailed in a standardized record, and these records were the source of data for this study. 
The data used were supplied by the regional public administration and were fully anonymized. The data set was composed of all of the assessments of the dependence status performed consecutively in the study area by a trained examiner (health professional) over a 16-week period in $2012(n=323)$; these evaluations were conducted in the spring and summer. Using a retrospective chart review, the records of these assessments were physically retrieved and comprehensively reviewed. Out of all of these assessments, 102 assessments were then excluded because the participants were $<50$ years $(n=19)$, were institutionalized $(n=62)$, or did not have a disability in ADLs $(n=21)$. The resultant sample was 221 participants. Using a detailed form, the data extracted included measures on the homebound status and the independent variables classified into the following dimensions: demographic, clinical, functional, and environmental factors.

\section{Ethical approval}

The study protocol obtained ethical approval from the Ethics Committee for Clinical Research of Galicia. No identifiable information was collected. All of the data were fully anonymized. The confidentiality of the participants was preserved in accordance with the current Spanish Data Protection Law (15/1999).

\section{Homebound status}

The homebound status was evaluated by asking the participants how many days they left their home during the previous week. The caregiver answered this question when the participant had any cognitive impairment according to the Short Portable Mental Status Questionnaire (SPMSQ), which is a 10-item questionnaire with a total score ranging from 0 to 10 . Cognitive impairment is indicated with a score $\geq 3$ points. ${ }^{15}$ In line with previous studies, ${ }^{8,12}$ the participants were considered homebound if they remained inside their home during the previous week or if they went out only for health care purposes (e.g., medical consultation or health emergencies).

\section{Factors}

\section{Clinical factors}

Mental status was measured using the Spanish-language version of SPMSQ. Walking ability was assessed by the Barthel Index ${ }^{16}$; this variable was dichotomized as independent versus limitation (e.g., personal help, wheelchair use, or immobile). Physician-diagnosed chronic conditions were obtained by reviewing the medical records of the participants with a checklist containing seven major groups. The impairments were assessed by medical records and interviews. Visual impairment was defined as a limited ability to read normally or vision loss. Hearing impairment included hypoacusia or auditory loss.

\section{Functional factors}

The Katz Index was used to assess the ability to perform six ADLs without personal assistance. $^{14}$ A dependence-level score was created by adding the number of ADLs requiring personal assistance (ranging 0-6), with higher scores reflecting greater dependence.

\section{Environmental factors}

Several environmental factors were analyzed, including the population size, a history of a change of home within last 5 years, and the type of housing. The architectural factors of the home entrance were evaluated; using an observational assessment, the presence of the following architectural barriers at the entryway was determined (yes/no): entrance with one or two steps and/or a high threshold $(>2 \mathrm{~mm}$ ), stairs (with at least three steps), a narrow door (clearance $<0.80 \mathrm{~m}$ ), and a heavy door. We analyzed the information about the primary caregiver, including two dichotomous variables (i.e., living with the participant and employment status). Formal care support was assessed as follows: personal help with ADLs from a public care service or with paid help (yes/no) 
Demographics

Demographic data were collected, including gender, age, living arrangements, and children.

\section{Data analysis}

Bivariate analyses were carried out to identify the determinants of homebound status. The associations were tested by a chi-square test for the categorical variables and by a Student's $t$-test for the continuous variables. All of the variables with a $p$-value $<0.05$ were then entered into a multivariate logistic regression analysis. The crude and adjusted ORs with $95 \%$ confidence intervals (CIs) were calculated. The Nagelkerke $R$-Square was calculated. SPSS 20.0 was used. The level of significance was $p<0.05$.

\section{Results}

Table 1 describes the characteristics of the 221 participants. The median SPMSQ score was 4 , representing mild cognitive impairment. More than half of the participants presented walking limitations $(57 \%)$. The participants were dependent in most of the ADLs studied. The most common barrier was the presence of one or two steps and/or high thresholds (67.9\%) (Table 2). 
Table 1. Homebound status according to demographic, clinical, and functional characteristics of the study population

\begin{tabular}{|c|c|c|c|c|}
\hline Characteristics & $\begin{array}{l}\text { Total sample } \\
(n=221)\end{array}$ & $\begin{array}{l}\text { Homebound status } \\
(n=88)\end{array}$ & $\begin{array}{l}\text { Non-homebound group } \\
(n=133)\end{array}$ & $p$-value \\
\hline \multicolumn{5}{|l|}{ Gender } \\
\hline Female & $154(69.7)$ & $64(72.7)$ & $90(67.7)$ & 0.423 \\
\hline Age $(y r)^{a}$ & $84(80-89)$ & $87(82-90.75)$ & $83(79-88)$ & 0.002 \\
\hline \multicolumn{5}{|l|}{ Living arrangement } \\
\hline Living alone & $47(21.3)$ & $20(22.7)$ & $27(20.3)$ & 0.134 \\
\hline Living with spouse only & $42(19.0)$ & $11(12.5)$ & $31(23.3)$ & \\
\hline Living with others & $132(59.7)$ & $57(64.8)$ & $75(56.4)$ & \\
\hline \multicolumn{5}{|l|}{ Children } \\
\hline Yes & $193(87.3)$ & $74(84.1)$ & $119(89.5)$ & 0.239 \\
\hline \multicolumn{5}{|l|}{ Mental function } \\
\hline SPMSQ: total score ${ }^{\mathrm{a}}$ & $4(1-7)$ & $4(1-8)$ & $4(1-6)$ & 0.258 \\
\hline \multicolumn{5}{|l|}{ Impairments } \\
\hline Hearing impairment & $43(19.5)$ & $21(23.9)$ & $22(16.5)$ & 0.178 \\
\hline Visual impairment & $19(8.6)$ & $5(5.7)$ & $14(10.5)$ & 0.209 \\
\hline \multicolumn{5}{|l|}{ Walking ability } \\
\hline $\begin{array}{l}\text { Independent at least } 50 \mathrm{~m} \text { on a level } \\
\text { surface }^{\mathrm{b}}\end{array}$ & $95(43.0)$ & $25(28.4)$ & $70(52.6)$ & $p<0.001$ \\
\hline \multicolumn{5}{|l|}{ Chronic medical condition (present) } \\
\hline Musculoskeletal disease & $139(62.9)$ & $62(70.5)$ & $77(57.9)$ & 0.058 \\
\hline Neurological (excluding dementia) & $77(34.8)$ & $29(33.0)$ & $48(36.1)$ & 0.632 \\
\hline Cardiac disease & $76(34.4)$ & $35(39.8)$ & $41(30.8)$ & 0.171 \\
\hline Pulmonary disease & $57(25.8)$ & $23(26.1)$ & $34(25.6)$ & 0.924 \\
\hline Diabetes mellitus & $56(25.3)$ & $27(30.7)$ & $29(21.8)$ & 0.137 \\
\hline Depression & $38(17.2)$ & $17(19.3)$ & $21(15.8)$ & 0.496 \\
\hline $\begin{array}{l}\text { Cancer (excluding minor skin } \\
\text { cancer) }\end{array}$ & $32(14.5)$ & $15(17.0)$ & $17(12.8)$ & 0.378 \\
\hline \multicolumn{5}{|l|}{ Functional status } \\
\hline $\begin{array}{l}\text { No. ADLs requiring personal } \\
\text { assistance }^{\mathrm{a}, \mathrm{c}}\end{array}$ & $4(2-5)$ & $5(3-6)$ & $3(2-5)$ & 0.002 \\
\hline
\end{tabular}

Data are presented as $n(\%)$ unless otherwise stated. SPMSQ, Short Portable Mental Status Questionnaire. ADLs, activities of daily living. Bold values denote statistical significance.

${ }^{a}$ Median (interquartile range).

${ }^{\mathrm{b}} 15$ points in the Barthel Index.

${ }^{c}$ Based on the Katz Index.

Data source: Office for Legal Certification of Long-term Care Need of Coruña (Spain). 
Table 2. Homebound status according to environmental factors

\begin{tabular}{|c|c|c|c|c|}
\hline Environmental factors & $\begin{array}{l}\text { Total sample } \\
(n=221)\end{array}$ & $\begin{array}{l}\text { Homebound status } \\
(n=88)\end{array}$ & $\begin{array}{l}\text { Non-homebound group } \\
(n=133)\end{array}$ & $p$-value \\
\hline \multicolumn{5}{|l|}{ Population size ${ }^{\mathrm{a}}$} \\
\hline Town size $\leq 10,000$ inhabitants & $44(19.9)$ & $14(15.9)$ & $30(22.6)$ & 0.217 \\
\hline $\begin{array}{l}\text { Town size from } 10,001 \text { to } 50,000 \\
\text { inhabitants }\end{array}$ & $52(23.5)$ & $18(20.5)$ & $34(25.6)$ & \\
\hline $\begin{array}{l}\text { Town size } \geq 50,001 \text { inhabitants (city } \\
\text { of Coruña) }\end{array}$ & $125(56.6)$ & $56(63.6)$ & $69(51.9)$ & \\
\hline $\begin{array}{l}\text { History of change of home within last } 5 \\
\text { years }\end{array}$ & $44(19.9)$ & $14(15.9)$ & $30(22.6)$ & 0.226 \\
\hline \multicolumn{5}{|l|}{ Type of housing } \\
\hline Multi-dwelling house & $125(56.6)$ & $57(64.8)$ & $68(51.1)$ & 0.053 \\
\hline Single-family house & $96(43.4)$ & $31(35.2)$ & $65(48.9)$ & \\
\hline \multicolumn{5}{|l|}{ Home entrance: barriers (present) } \\
\hline $\begin{array}{l}\text { One or two steps and/or high } \\
\text { threshold }\end{array}$ & $150(67.9)$ & $65(73.9)$ & $85(63.9)$ & 0.121 \\
\hline Stairs, without ramp/elevator/stair-lift & $91(41.2)$ & $57(64.8)$ & $34(25.6)$ & $p<0.001$ \\
\hline Narrow door & $104(47.1)$ & $48(54.5)$ & $56(42.1)$ & 0.070 \\
\hline Heavy door (no power-assisted door) & $33(14.9)$ & $20(22.7)$ & $13(9.8)$ & 0.008 \\
\hline \multicolumn{5}{|l|}{ Primary caregiver } \\
\hline Living with participant (co-resident) & $145(65.6)$ & $58(65.9)$ & $87(65.4)$ & 0.939 \\
\hline Currently employed & $81(36.7)$ & $37(42.0)$ & $44(33.1)$ & 0.176 \\
\hline \multicolumn{5}{|l|}{ Formal care support received in ADLs } \\
\hline Public care service or paid help & $105(47.5)$ & $47(53.4)$ & $58(43.6)$ & 0.153 \\
\hline
\end{tabular}

Data are presented as $n(\%)$. ADLs, activities of daily living. Bold values denote statistical significance.

${ }^{a}$ Classed using Spanish census information.

Data source: Office for Legal Certification of Long-term Care Need of Coruña (Spain).

The prevalence of the homebound status was 39.8\%. For different reasons other than health care, the participants left their homes 3 days during the previous week (median; interquartile range: $0-7)$. The homebound participants were older compared with the non-homebound group ( $p$ $=0.002)($ Table 1$)$.

The homebound group was more likely to have a walking limitation compared with the nonhomebound group $(p<0.001)$ (Table 1$)$. The number of ADLs requiring personal assistance was higher in the homebound participants $(p=0.002)$ (Table 1). The environmental factors associated with being homebound were the presence of stairs $(p<0.001)$ and a heavy door $(p=0.008)$ (Table 2).

Table 3 shows the results of the multivariate analysis. An advanced age $(p=0.04)$, walking ability limitations $(p=0.006)$, the presence of stairs $(p<0.001)$, and a heavy door $(p=0.023)$ remained associated significantly with homebound status. More than $33 \%$ of the variation was explained ( $R$-Square: 0.34$)$. 
Table 3. Crude and adjusted ORs and 95\% CIs of the associations between homebound status and demographic, clinical, functional, and environmental factors $(n=221)$

\begin{tabular}{|c|c|c|c|c|}
\hline \multirow{2}{*}{ Independent variables } & \multicolumn{2}{|l|}{ Crude } & \multicolumn{2}{|c|}{ Adjusted } \\
\hline & OR & $95 \% \mathrm{CI}$ & OR & $95 \% \mathrm{CI}$ \\
\hline \multicolumn{5}{|l|}{ Demographic factors } \\
\hline Age (yr) & 1.06 & $1.02-1.11$ & 1.05 & $1.00-1.10^{*}$ \\
\hline \multicolumn{5}{|l|}{ Clinical factors } \\
\hline \multicolumn{5}{|l|}{ Walking ability } \\
\hline Independent at least $50 \mathrm{~m}$ (level surface) & 1.00 & & 1.00 & \\
\hline Limitation $^{\mathrm{a}}$ & 2.80 & $1.58-4.98$ & 3.26 & $1.40-7.62^{*}$ \\
\hline \multicolumn{5}{|l|}{ Functional status } \\
\hline No. ADLs requiring personal assistance ${ }^{\mathrm{b}}$ & 1.30 & $1.10-1.55$ & 1.08 & $0.84-1.38$ \\
\hline \multicolumn{5}{|l|}{ Environmental factors } \\
\hline \multicolumn{5}{|l|}{ Stairs, without ramp/elevator/stair-lift } \\
\hline No & 1.00 & & 1.00 & \\
\hline Barrier present at entrance & 5.35 & $2.98-9.62$ & 6.67 & $3.42-13.03^{\S}$ \\
\hline \multicolumn{5}{|l|}{ Heavy door (no power-assisted door) } \\
\hline No & 1.00 & & 1.00 & \\
\hline Barrier present at entrance & 2.72 & $1.27-5.80$ & 2.83 & $1.15-6.95^{*}$ \\
\hline
\end{tabular}

${ }^{\ddagger} p<0.05,{ }^{\S} p<0.001$. Hosmer-Lemeshow test $p$-value for the adjusted model $=0.61$. CI, confidence interval. ADLs, activities of daily living.

Bold values denote statistical significance.

${ }^{a} \leq 10$ points in the Barthel Index.

${ }^{\mathrm{b}}$ Based on the Katz Index. Logistic analysis; homebound status = 1, non-homebound (participants who left their home $\geq 1$ times for a reason other than for health care reasons in the previous week) $=0$.

Data source: Office for Legal Certification of Long-term Care Need of Coruña (Spain).

\section{Discussion}

Using data from a sample of Spanish middle-aged and older people with disabilities in ADLs, the findings indicated that nearly $40 \%$ of the participants were homebound. This is the first study exploring the prevalence of the homebound status and the factors associated in this population group. The results confirmed that the homebound status is a multidimensional construct. Older age, walking limitations, and architectural factors were independently associated with being homebound.

Most of the previous studies have used a definition of the homebound status based on selfreporting of the frequency of going outdoors. ${ }^{6,17}$ However, this study focused on people who remained inside the home during the previous week. The findings showed that the homebound status was a highly prevalent problem in the study population. The current concept of health of the World Health Organization (WHO) includes areas of life such as interpersonal interactions and community life. ${ }^{18}$ Accordingly, the study findings showed that many participants did not carry out important activities for health in the previous week according to the biopsychosocial model of the WHO. ${ }^{18}$ The proportion of homebound people among people with disabilities in ADLs was much higher than the estimates made in the general older population ${ }^{1,4,8-11}$ and in frail older people however, it is important to emphasize that our sample was characterized by an advanced mean age, a high frequency of chronic health conditions, and the combination of motor and mental impairments. These characteristics are common in the group of people with disabilities in ADLs. ${ }^{19-22}$ The comparisons between the results with previous research are complicated due to the considerable differences in the study populations and the heterogeneity of the definitions of homebound status. ${ }^{6}$ 
Not surprisingly, increasing age was significantly associated with being a homebound person, consistent with previous research conducted with older people. ${ }^{1,4,9,13}$ Regarding mobility skills, the multivariate analysis showed that independence in walking activity is a crucial element in the task of going outside. Ambulation disorders were significantly more frequent in the homebound group compared to the non-homebound subjects. Moreover, motor impairment was the most common limitation among the participants. Previous studies have reported an association between walking ability limitations and homebound status among older people. ${ }^{1,8,11,13,23}$ However, it is possible that this relation is bidirectional because homebound status may lead to greater walking limitations in the future, as a consequence of the negative effects of the reduction in physical activity and movement (e.g., loss of strength and endurance). ${ }^{24-27}$

Households were systematically observed using a more comprehensive list of barriers compared to previous studies. ${ }^{1,10}$ Two features of the architectural environment were important predictors of the homebound status. Homebound participants were more likely to have stairs and heavy doors at the entryway to their homes. These findings were consistent with the scarce evidence currently available on this topic. ${ }^{1,10}$ This study supported the bidirectionality of the interplay person-context, corroborating previous models. Verbrugge and Jette emphasized that a disability can be alleviated by increasing personal capacity or by reducing environmental demand (e.g., through home modifications). ${ }^{28}$ The WHO postulated that disability arises from the bidirectional interaction between health conditions and contextual factors. ${ }^{18} \mathrm{~A}$ recent model established that the life space restriction occurs when people present a limitation in physiologic reserve/capacity to meet environmental challenges, such as architectural barriers. ${ }^{29}$ Accordingly, we can conclude that health services should pay more attention to the role of environmental factors. Advice on home adaptations may be a useful intervention for this population, consistent with previous literature on the benefits of environmental modification. The architectural factors at the entryway influence the likelihood of reporting difficulty going outside. For example, stairs intervene as a barrier for walker users, and ramps are a facilitator for wheelchair users. ${ }^{30}$ Some clinical trials have shown that the removal of architectural barriers, such as stairs, slowed the dependence on $\mathrm{ADLs}^{31}$ and decreased the incidence of falls ${ }^{32,33}$ and the costs of certain health and social services. ${ }^{31}$

Some limitations should be mentioned. The study design did not allow inferences on causal relationships. The lack of data on other potentially important factors, such as comorbidity or socioeconomic status, was also a weakness. A recent study found a significant association between comorbidity and homebound status. ${ }^{1}$ In addition, future studies need to consider socioeconomic status. Other reports have shown that the lowest financial status was associated with homebound status. ${ }^{1,11,34}$ It is possible that people with lower family incomes are more likely to report unmet needs for home adaptations; also, people with a better socioeconomic status may have better access to prevention and rehabilitation services. Finally, the participants were recruited from one region in Spain. The study population consisted of people applying for long-term care need certification, thus making it difficult to generalize the results to all Spanish regions and for the entire population of people with disabilities in ADLs. Because of the inclusion of people applying for long-term care services, the results might be more representative of people with the most severe degrees of disabilities in ADLs, characterized by a greater need for the services of professional care compared with the people with a slight disability.

Although the findings need to be confirmed in longitudinal studies, this study identified several risk factors, suggesting the complexity of the homebound status and the need for multicomponent and multidisciplinary approaches. As independence in ambulation was a significant protective factor, community-based strategies aimed at mobility skills (e.g., a home exercise program and rehabilitation) might prevent or delay being homebound. A careful clinical assessment of the individual skills and of the potential for rehabilitation by specialized teams is essential to establish adequate preventive and intervention strategies. Assistive technology for mobility may be another intervention to consider. Mobility devices, such as a walker or a power wheelchair, can act as enablers to independence and safety ${ }^{35}$; these programs could include a needs assessment and training in the use of such devices. Moreover, the results shed light on the need to consider architectural factors. This study suggested the need for the development of interventions aimed at reducing architectural barriers through a comprehensive home assessment of the environmental risks and the individualized advice on home adaptations. On a social level, policies promoting 
universal design and age-friendly homes play an important role for older people as well as people of all ages. ${ }^{36}$

\section{Conclusion}

The homebound status is a very common problem among middle-aged and older adults with disabilities in ADLs. Two architectural factors in the home entrance and walking ability limitations were found to be important risk factors, suggesting that more emphasis on home adaptations and mobility skills is needed as a means to preventing or decreasing the homebound status.

\section{References}

1. Cohen-Mansfield J, Shmotkin D, Hazan H. Homebound older persons: prevalence, characteristics, and longitudinal predictors. Arch Gerontol Geriatr. 2012;54(1):55-60.

2. Choi K, Park E, Lee IS. Homebound status and related factors according to age in female elders in the community. J Korean Acad Nurs. 2012;42(2):291-301.

3. Cohen-Mansfield J, Shmotkin D, Hazan H. The effect of homebound status on older persons. J Am Geriatr Soc. 2010;58(12):2358-2362.

4. Ganguli M, Fox A, Gilby J, Belle S. Characteristics of rural homebound older adults: a community-based study. J Am Geriatr Soc. 1996;44(4):363-370.

5. Kono A, Kai I, Sakato C, Rubenstein LZ. Frequency of going outdoors: a predictor of functional and psychosocial change among ambulatory frail elders living at home. J Gerontol A Biol Sci Med Sci. 2004;59(3):275-280.

6. Qiu WQ, Dean M, Liu T, et al. Physical and mental health of homebound older adults: an overlooked population. J Am Geriatr Soc. 2010;58(12):2423-2428.

7. Fujita K, Fujiwara Y, Chaves PHM, Motohashi Y, Shinkai S. Frequency of going outdoors as a good predictors for incident disability of physical function as well as disability recovery in community-dwelling older Adults in rural Japan. J Epidemiol. 2006;16(6):261-270.

8. Herr M, Latouche A, Ankri J. Homebound status increases death risk within two years in the elderly: results from a national longitudinal survey. Arch Gerontol Geriatr. 2013;56(1):258-264.

9. Kawamura K, Watanabe M, Watanabe T, et al. Incidence of disability in housebound elderly people in a rural community in Japan. Geriatr Gerontol Int. 2005;5:234-241.

10. Lindesay J, Thompson C. Housebound elderly people: definition, prevalence and characteristics. Int J Geriatr Psychiatry. 1993;8:231-237.

11. Murayama H, Yoshie S, Sugawara I, Wakui T, Arami R. Contextual effect of neighborhood environment on homebound elderly in a Japanese community. Arch Gerontol Geriatr. 2012;54:67-71.

12. Harada K, Lee S, Park H, et al. Going outdoors and cognitive function among community-dwelling older adults: moderating role of physical function. Geriatr Gerontol Int. 2016;16:65-73.

13. Inoue K, Matsumoto M. Homebound status in a community-dwelling elderly population in Japan. Asia Pac J Public Health. 2001;13(2):109-115.

14. Katz S, Ford A, Moskowitz R, Jackson B, Jaffe M. The index of ADL: a standardized measure of biological and psychosocial function. JAMA. 1963;185:914-919.

15. Martínez J, Dueñas R, Onís MC, et al. Adaptación y validación al castellano del cuestionario de Pfeiffer (SPMSQ) para detectar la existencia de deterioro cognitivo en personas mayores de 65 años. Med Clin (Barc). 2001;117:129-134.

16. Mahoney FI, Barthel DW. Functional evaluation: the Barthel index. Md State Med J. 1965;14:61-65.

17. Hirai H, Kondo K. Review of the literature on the 'Tojikomori' elderly in Japan study trends, definition, and review of cohort studies. Nihon Koshu Eisei Zasshi. 2007;54(5):293-303.

18. World Health Organization. International Classification of Functioning, Disability and Health. Geneva: World Health Organization; 2001.

19. Alexandre TS, Corona LP, Nunes DP, et al. Gender differences in incidence and determinants of disability in activities of daily living amongelderly individuals: SABE study. Arch Gerontol Geriatr. 2012;55(2):431-437.

20. Guerra RO, Alvarado BE, Zunzunegui MV. Life course, gender and ethnic inequalities in functional disability in a Brazilian urban elderly population. Aging Clin Exp Res. 2008;20(1):53-61. 
21. Konno K, Katsumata Y, Arai A, Tamashiro H. Functional status and active life expectancy among senior citizens in a small town in Japan. Arch Gerontol Geriatr. 2004;38(2):153-166.

22. Rodríguez S, Montero P, Carmenate M, Avendano M. Functional decline over 2 years in older Spanish adults: evidence from the survey of health, ageing and Retirement in Europe. Geriatr Gerontol Int.2014;14:403-412.

23. Fujita K, Fujiwara Y, Kumagai S, et al. The frequency of going outdoors, and physical, psychological and social functioning among community-dwelling older adults. Nippon Koshu Eisei Zasshi. 2004;51(3):168-180.

24. LIFE Study Investigators. Effects of a physical activity intervention on measures of physical performance: results of the Lifestyle Interventions and Independence for Elders Pilot (LIFE-P) study. J Gerontol A Biol Sci Med Sci. 2006;61A(11):1157-1165.

25. Simonsick EM, Guralnik JM, Volpato S, Balfour J, Fried LP. Just get out the door! Importance of walking outside the home for maintaining mobility: findings from the Women's Health and Aging Study. J Am Geriatr Soc. 2005;53:198-203.

26. Tikkanen P, Nykänen I, Lönnroos E, et al. Physical activity at age of 20-64 years and mobility and muscle strength in old age: a community-based study. J Gerontol A Biol Sci Med Sci. 2012;67(8):905-910.

27. Visser M, Pluijm SMF, Stel VS, Bosscher RJ, Deeg DJH. Physical activity as a determinant of change in mobility performance: the Longitudinal Aging Study Amsterdam. J Am Geriatr Soc. 2002;50(11):1774-1781.

28. Verbrugge LM, Jette AM. The disablement process. Soc Sci Med.1994;38(1):1-14.

29. Xue QL, Fried LP, Glass TA, Laffan A, Chaves PHM. Life-Space constriction, development of frailty, and the competing risk of mortality: the women's health and aging study I. Am J Epidemiol. 2007;167(2):240-248.

30. Clarke PJ. The role of the built environment and assistive devices for outdoor mobility in later life. J Gerontol B Psychol Sci Soc Sci.2014;69(7):S8-S15.

31. Mann WC, Ottenbacher KJ, Fraas L, Tomita M, Granger CV. Effectiveness of assistive technology and environmental interventions in maintaining independence and reducing home care costs for the frail elderly. A randomized controlled trial. Arch Fam Med. 1999;8(3):210-217.

32. Cumming RG, Thomas M, Szonyi G, et al. Home visits by an occupational therapist for assessment and modification of environmental hazards: a randomized trial of falls prevention. J Am Geriatr Soc. 1999;47(12):1397-1402.

33. Nikolaus T, Bach M. Preventing falls in community-dwelling frail older people using a home intervention team (HIT): results from the randomized Falls-HIT trial. J Am Geriatr Soc. 2003;51(3):300-305.

34. Jensen G, Silver H, Roy MA, et al. Obesity is a risk factor for reporting homebound status among community-dwelling older persons. Obesity. 2006;14(3):509-517.

35. Salminen A, Brandt A, Samuelsson K, Töytäri O, Malmivaara A. Mobility devices to promote activity and participation: a systematic review. J Rehabil Med. 2009;41(9):697706.

36. Carr K, Weir PL, Azar D, Azar NR. Universal design: a step toward successful aging. J Aging Res. 2013;2013:324624. 